\title{
Epikeratophakia for aphakia, keratoconus, and myopia
}

\author{
Brett L Halliday
}

\begin{abstract}
A series of 67 cases of epikeratophakia is presented with an average time from surgery of 12.2 months. For aphakia there was a delay in the recovery of vision, but by nine months $83 \%$ of 57 patients achieved an acuity equal to, or within 1 line of, the preoperative value. $57 \%$ were corrected to within 3 dioptres of emmetropia, but in the latter part of the series $75 \%$ were within this range. Astigmatism and reduced contrast sensitivity, especially in the presence of glare, were important complications. For keratoconus, $86 \%$ of seven patients with over two months of follow-up achieved a spectacle corrected acuity of $6 / 9$ or better. One patient had surgery for myopia and obtained the desired refractive correction.
\end{abstract}

Barraquer pioneered the use of the cryolathe in refractive surgery about 30 years ago. His technique of keratomileusis never gained widespread popularity. In contrast, epikeratophakia, introduced in 1980, has been taken up enthusiastically, especially in the United States. By 1986 over 1500 surgeons had been certified by Allergan Medical Optics (California, USA) to use their epikeratophakia lenses.

Keratomileusis failed to become widely accepted owing to problems with the technique. The range of refractive correction is limited to. about 12 dioptres, and the surgical technique is invasive, with a lamellar disc of the patient's own cornea turned on a cryolathe to provide the refractive correction. Complications associated with keratomileusis include corneal perforation and cryolathe damage to the lamellar disc.

In contrast, epikeratophakia has a wide range of possible correction (up to about 30 dioptres of hyperopia or myopia), is largely non-invasive, and is usually reversible. Cryolathe lens manu-

Moorfields Eye Hospital, London ECIV 2PD

B L Halliday

Correspondence to: B L Halliday, FRCS.

Accepted for publication 23 August 1989 facture may be centralised, allowing surgery to be performed by any corneal surgeon without requiring specialised equipment. Epikeratophakia with a plano lens may also be used to treat certain cases of keratoconus.

Although there have been some case reports of failed epikeratophakia, ${ }^{1-3}$ large published series (mostly from the United States) have generally concluded that epikeratophakia is a worthwhile procedure. ${ }^{4-13}$ Despite this, the number of British surgeons performing the technique remains very small.

This paper presents a series of all the cases of epikeratophakia performed by the author to date and defines the categories of patients who may benefit from this procedure.

\section{Patients and methods}

\section{SELECTION OF PATIENTS}

Patients were referred to the corneal clinic at Moorfields Eye Hospital where they were assessed as potential candidates for surgery. Epikeratophakia was only considered when simpler alternatives such as spectacle or contact lens correction were considered inappropriate. Most patients had tried and failed contact lens wear, though in a few monocularly aphakic children, where contact lens correction was thought likely to fail, epikeratophakia was performed as the primary treatment.

Adult monocular aphakes suitable for surgery included those who had had previous intracapsular extraction on one eye followed by extracapsular extraction with intraocular implant on the fellow eye. Other potentially suitable patients included those with a history of uveitis who had had extracapsular surgery performed electively without lens implant and those who were aphakic following traumatic cataract. Bilateral aphakia was considered as an indication for epikeratophakia only in patients intolerant of a contact lens who preferred to remain uncorrected rather than wear spectacles.

Keratoconus patients whose corneal irregularity was such that spectacle correction was impossible, yet who had good acuity with a diagnostic contact lens, were considered ideal candidates for surgery. Patients with enough central scar to reduce contact lens acuity were treated by penetrating keratoplasty.

Patients who were equally myopic in each eye were not considered suitable candidates for 
surgery, as without exception they were managing with either contact lenses or spectacles. Monocular myopes who were uncorrected in their myopic eye were considered for surgery on the myopic eye, as were those with one eye markedly more myopic than the other.

In all cases the referring surgeon felt that the more invasive surgical alternatives, such as secondary intraocular lens implantation for aphakia, penetrating keratoplasty for keratoconus, or radial keratotomy for myopia, were contraindicated.

\section{LENS MANUFACTURE}

For the first six procedures commercially produced lenses were imported from the United States. For the remainder lenses were manufactured by the author using donor corneas that had been stored either in K-Sol or McCareyKaufman storage medium.

A typical epikeratophakia lens has a central optical zone and a thin peripheral wing which is sutured to hold the lens in place. Most of the lenses were made with a specially developed cryolathe (Citycrown Sales, 14 Kempston Close, Gatehouse Way, Aylesbury, Buckinghamshire), which has a facility for automatically making a smooth transition between the radius of cut used for the optical zone and the radius used for the wing. Thirteen lenses were made on a lathe without this facility, and for these the transition between optical zone and wing was made manually. Alternatively, lenses were made with a single radius of cut, so that the optical zone in these extended to the edge of the lens. ${ }^{14}$ Detailed descriptions of the formulae used to lathe the lenses has been published. ${ }^{14-16}$

\section{SURGICAL TECHNIQUE}

The basic technique of epikeratophakia consists of initially removing corneal epithelium, then dissecting a peripheral pocket for the wing of the lens, which is then sutured in place. The exact technique employed evolved over this series.

Thorough removal of corneal epithelium is necessary so that there is no subsequent cellular proliferation at the interface between the epikeratophakia lens and host cornea. Epithelium peripheral to the lens should be left intact, as it is

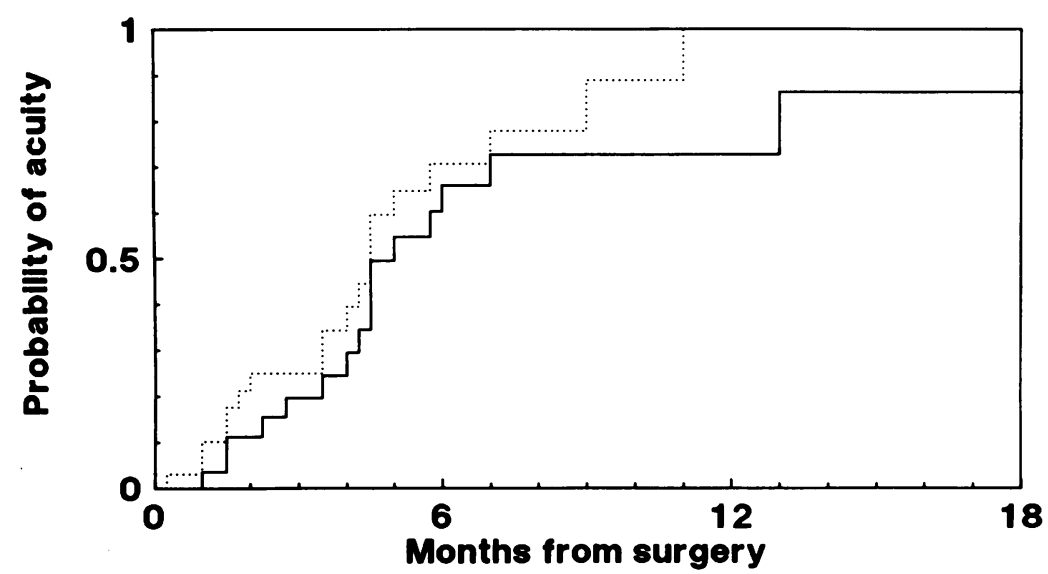

Figure 2: The probability of an aphakic patient achieving a visual acuity of 6/12 (dotted line) and $6 / 9$ (solid line) is plotted against time for surgery. from this peripheral cornea that epithelial regeneration covers the epikeratophakia lens. Failure of prompt re-epithelialisation may be associated with melting of the lens and infective keratitis. For the initial seven cases absolute alcohol was used to drench the patient's cornea to aid removal of the epithelium. Unfortunately this proved to be associated with delay in subsequent re-epithelialisation. Subsequently a scalpel blade was used to remove epithelium, and the use of alcohol was confined to a final wipe with a barely damp swab, care being taken to avoid peripheral cornea.

The next step in the operation is to create a pocket for the insertion of the wing of the lens. In most cases a 7 or $7.5 \mathrm{~mm}$ diameter HessburgBaron suction trephine was used to make a partial thickness trephination to a depth of about $180 \mu \mathrm{m}$. A 21 gauge needle, bent to $90^{\circ} 2 \mathrm{~mm}$ from the end, was then used to dissect a pocket, parallel to the corneal surface, from the base of the partial thickness trephination extending peripherally. In the initial four cases an annular wedge of cornea was removed from the inside edge of the trephination. In 10 cases no trephine was used. For these cases after circular mark had been made on the cornea an annulus (of Bowman's layer and underlying corneal stroma) was excised with a razor blade and Paufique's knife. This approach was used for some of the 13 lenses made without a peripheral wing, which were simply sewn on to the surface of the cornea, allowing the 'bare area' of the annulus to approximate the deep surface of the lens. ${ }^{14}$

The final part of the operation is to fix the lens in place. In all but two cases this was done with 10-0 monofilament sutures. Initially 16 sutures were used, but it soon became apparent that eight sutures were usually sufficient. Exceptionally up to 24 sutures were used for those lenses made without a peripheral wing that were sewn on to the surface of the cornea. In two cases a fibrin glue (Tisseal; Immuno Ltd, Sevenoaks, Kent) was used to fix the lens in place of sutures. For aphakia and myopia the sutures were not tied tightly. For keratoconus very tight sutures were tied while an assistant pressed firmly to reduce the ectatic cornea.

For all the keratoconus cases the sutures were

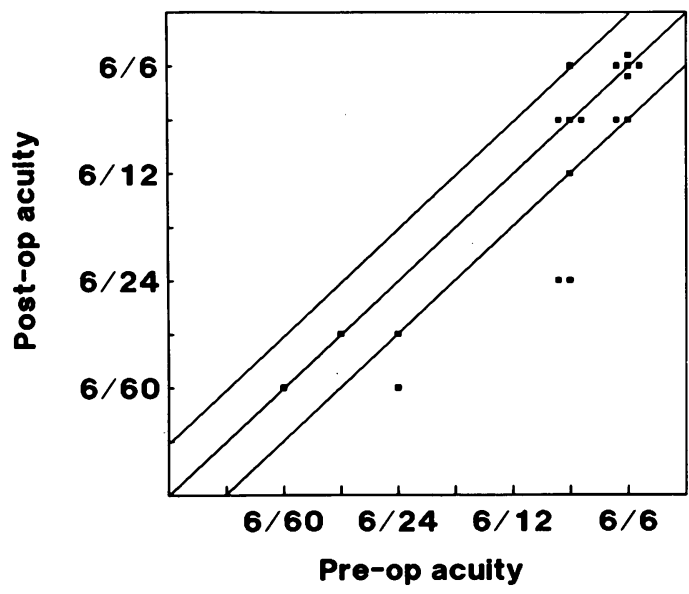

Figure 3: Scattergram showing postoperative acuity against preoperative acuity for all aphakic patients with at least nine months of follow-up. 
tied with the help of an operative placido disc, sutures being added or removed as dictated by the symmetry of the reflex in an attempt to reduce induced astigmatism. This technique was also used for the most recent aphakic cases.

In all cases the operation was completed with a subconjunctival injection of antibiotic and the eye padded until the next morning. In 17 cases early in the series a bandage contact lens $(75 \%$ water content, back central optic radius $9 \mathrm{~mm}$, overall diameter $15 \mathrm{~mm}$ ) was used until the epithelium had regenerated to cover the cornea. Subsequently eyes have been left to epithelialise without the use of contact lenses, eye pads, or lid sutures. ${ }^{17}$

Postoperatively topical antibiotic and weak steroid drops were used, usually three times a day, for about eight weeks. During this time sutures were removed from the aphakic and myopic cases, but for keratoconus the sutures were left in place unless they became loose or were inducing astigmatism. Patients were refracted at regular intervals, starting as soon as the epikeratophakia lens had cleared sufficiently. To provide more information on visual function, selected patients had contrast sensitivity measurements in both the operated eye and in the fellow, normal eye. A computer controlled system was used with sinusoidal gratings displayed on a television monitor with an average luminance of $14 \mathrm{~cd} / \mathrm{m}^{2}$. As some patients had reported a reduction in vision in bright light, the measurements of contrast sensitivity were repeated in the presence of a glare source of luminance $300 \mathrm{~cd} / \mathrm{m}^{2}$ (Brightness Acuity Tester; Mentor Inc, USA).

\section{Results}

From October 1986 to May 1989, 67 epikeratophakia procedures were performed: 25 were for traumatic aphakia, 16 for aphakia following intracapsular cataract extraction, 12 for aphakia following congenital cataract extraction, 4 for aphakia following extracapsular cataract extraction, 9 for keratoconus, and 1 for myopia. The average age of the patients was 34 years (range 1

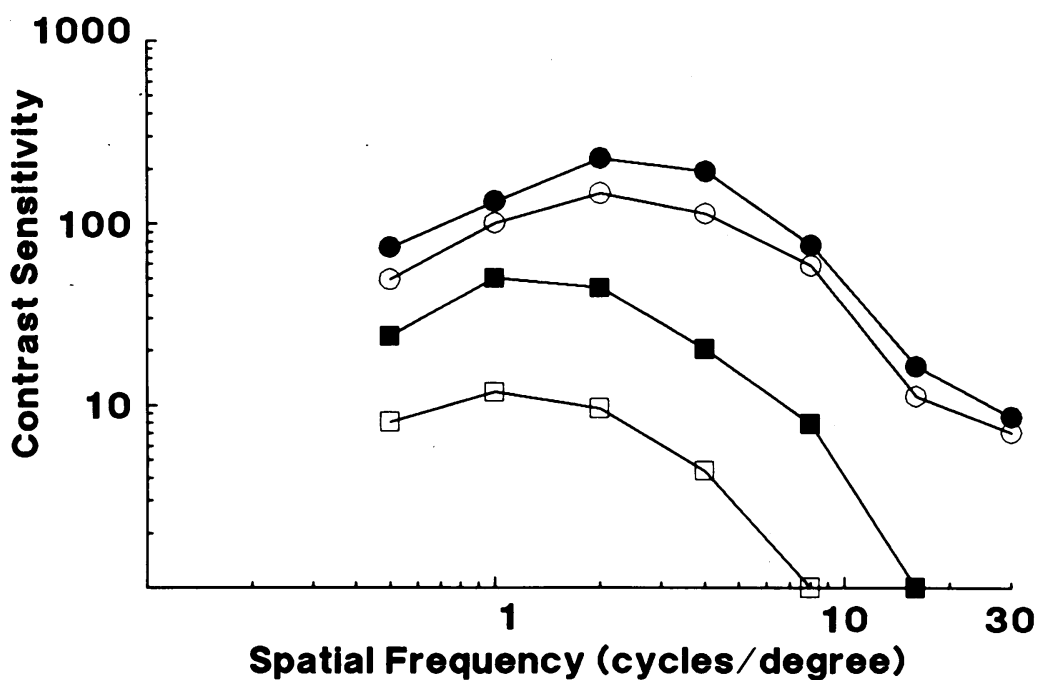

Figure 4: Contrast sensitivity is plotted against spatial frequency for a patient following aphakia epikeratophakia. Squares represent the epikeratophakia eye; circles represent the normal, fellow eye. Filled symbols indicate testing under normal conditions; open symbols indicate testing in the presence of glare. to 82). Figure 1 shows in detail the distribution of age and diagnosis. The average time from surgery was $12 \cdot 2$ months (range 1 to 32 ).

Most of the patients had an uneventful postoperative course, with rapid re-epithelialisation of the epikeratophakia lens and with steadily improving lens clarity paralleled by improvement in corrected visual acuity. Loosening of sutures was a very common complication, and these were removed as required.

The time taken for complete epithelialisation of 10 consecutive patients managed with a bandage contact lens was compared with the time taken by the next 10 patients managed without a contact lens. The contact lens group took an average of 3.9 days to complete epithelialisation (range 3 to 5 days), whereas the untreated group took 3.8 days (range 3 to 5 days). Re-epithelialisation when successful was complete by seven days postoperatively.

APHAKIA - VISUAL RESULT

Recovery of visual acuity after epikeratophakia is known to be slow. In this series the visual acuity of individual patients steadily improved over periods as long as a year after surgery. Twentyfive cases of epikeratophakia for aphakia with a preoperative acuity of at least $6 / 9$ were studied in detail to analyse this recovery of acuity. The average age in this group was 47 years (range 9-82). Survival (Kaplan-Meir type) analysis was used to plot the probability of achieving acuities of 6/12 and 6/9 at a given time after surgery (Fig 2 ). This shows that it took 4.4 months for $50 \%$ of cases to reach an acuity of $6 / 12$ and 4.8 months to reach $6 / 9$.

Figure 3 is a scattergram plotting postoperative against preoperative acuity for all aphakic cases with at least nine months of follow-up. Of the 18 cases plotted $11(61 \%)$ achieved their preoperative acuity and $15(83 \%)$ achieved an acuity within one line of the preoperative value. All of the three cases that failed to reach this level of acuity had clinically clear epikeratophakia lenses. One of these cases had developed disciform senile macular degeneration, one had a high cylinder (7 dioptres), and the other had no apparent reason for poor acuity.

Contrast sensitivity was measured in four patients. In every case the Snellen acuity in the epikeratophakic eye was $6 / 9$ or better, and this was not reduced by the presence of the glare source. Figure 4 shows a typical result. In the absence of glare the contrast sensitivity of the epikeratophakic eye was approximately $0.75 \mathrm{log}$ units worse than the phakic, fellow eye. In the presence of glare the relative deficit in the epikeratophakic eye increased to over $1 \log$ unit. Full details of the contrast sensitivity measurements in these patients have been published elsewhere. ${ }^{18}$

APHAKIA - REFRACTIVE RESULT

Figure 5 is a scattergram showing correction achieved (spherical equivalent, dioptres) against preoperative refraction. $57 \%$ of patients were corrected within 3 dioptres of the desired value. The remaining $43 \%$ were outside this range and 


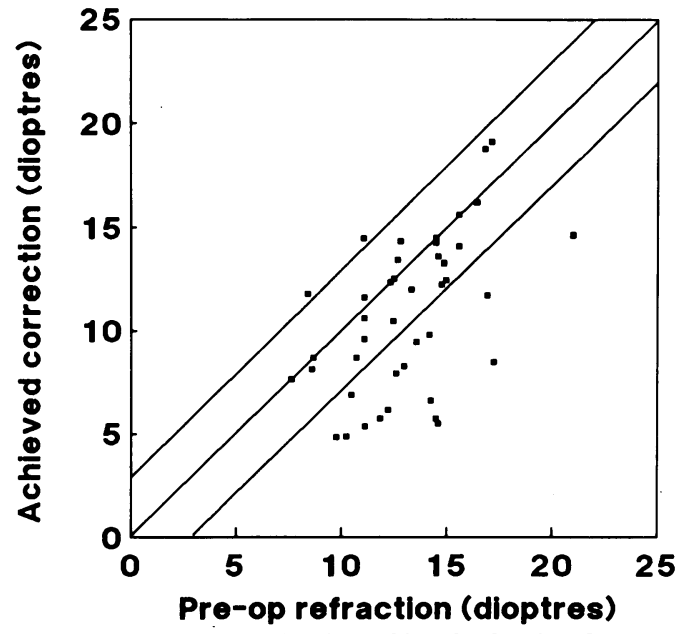

Figure 5: Scattergram showing achieved refractive change against preoperative refraction for aphakic patients.

thus, in general, unable to be satisfactorily corrected with spectacles. Results improved considerably as formulae for lathing were modified over the period of this study. For the first 12 lenses made only $25 \%$ were within 3 dioptres of the desired correction, whereas for the most recent 12 cases $75 \%$ were within this range.

Postoperative astigmatism varied from 0 to 8 dioptres. The average magnitude was 2.5 dioptres, with $43 \%$ of cases having a cylinder of over 3 dioptres. This problem has shown a tendency to improve over the duration of the study: $50 \%$ of the first 12 cases had a cylinder of over 3 dioptres, whereas for the most recent 12 cases, only $25 \%$ had cylinders over this value.

\section{PAEDIATRIC APHAKIA}

Sixteen cases of aphakic epikeratophakia were performed on children aged 10 years or under. Refractive and visual results, where available, have been included in Figures 2, 3, and 5. Table 1 provides more details. Nine out of 13 eyes refracted $(69 \%)$, were corrected to within 3 dioptres of emmetropia. Two children in this study were seriously undercorrected. Patient 6 had a microphthalmic eye and congenital cataract. Lensectomy was performed at age 1 month, but contact lens wear proved increasingly difficult so epikeratophakia was performed

TABLE I Results in paediatric aphakia

\begin{tabular}{lllllll}
\hline Patient no. & $\begin{array}{l}\text { Age } \\
\text { (years) }\end{array}$ & Diagnosis & $\begin{array}{l}\text { Follow-up } \\
\text { (months) }\end{array}$ & $\begin{array}{l}\text { Preop. } \\
\text { acuity }\end{array}$ & $\begin{array}{l}\text { Postop. } \\
\text { acuity }\end{array}$ & Postop. refraction \\
\hline 1 & 1 & $\mathrm{C}(\mathrm{U})$ & 7 & $\mathrm{NK}$ & $\mathrm{NK}$ & Approx plano \\
2 & 3 & $\mathrm{~T}$ & 7 & $\mathrm{NK}$ & $6 / 18$ & $5 \cdot 00 /-1 \cdot 00 \times 140$ \\
3 & 3 & $\mathrm{~T}$ & 1 & $\mathrm{NK}$ & $\mathrm{NK}$ & $\mathrm{NR}$ \\
4 & 3 & $\mathrm{~T}$ & 3 & $\mathrm{NK}$ & $\mathrm{NK}$ & $2 \cdot 00 \mathrm{sph}$ \\
5 & 3 & $\mathrm{~T}$ & 1 & $\mathrm{NK}$ & $\mathrm{NK}$ & $\mathrm{NR}$ \\
6 & 4 & $\mathrm{C}(\mathrm{U}, \mathrm{M})$ & 8 & $\mathrm{CF}$ & $6 / 60$ & $16 \cdot 00 /-2 \cdot 00 \times 90$ \\
7 & 5 & $\mathrm{~T}$ & 5 & $\mathrm{NK}$ & $6 / 18$ & $-2 \cdot 00 \mathrm{sph}$ \\
8 & 5 & $\mathrm{~T}$ & 1 & $\mathrm{NK}$ & $\mathrm{NK}$ & $6 \cdot 00 \mathrm{sph}$ \\
9 & 5 & $\mathrm{C}(\mathrm{U})$ & 3 & $\mathrm{CF}$ & $\mathrm{CF}$ & Approx plano \\
10 (left eye) & 7 & $\mathrm{C}(\mathrm{B})$ & 14 & $6 / 24$ & $6 / 36$ & $2 \cdot 50 /-4 \cdot 50 \times 180$ \\
10 (right eye) & 7 & $\mathrm{C}(\mathrm{B})$ & 5 & $6 / 60$ & $6 / 60$ & $2 \cdot 00 /-4 \cdot 00 \times 130$ \\
11 & 7 & $\mathrm{~T}$ & 2 & $6 / 12$ & $6 / 24$ & $2 \cdot 50 /-6 \cdot 00 \times 130$ \\
12 & 8 & $\mathrm{C}(\mathrm{B})$ & 22 & $6 / 60$ & $6 / 60$ & $-2 \cdot 00 \mathrm{sph}$ \\
13 & 8 & $\mathrm{~T}$ & 5 & $6 / 6$ & $6 / 12$ & $+10 \cdot 00 /-3 \cdot 25 \times 180$ \\
14 & 9 & $\mathrm{~T}$ & 6 & $6 / 6$ & $6 / 6$ & $+1 \cdot 00 /-1 \cdot 50 \times 25$ \\
15 & 10 & $\mathrm{C}(\mathrm{B})$ & 1 & $6 / 18$ & $\mathrm{NK}$ & $\mathrm{NR}$ \\
\hline
\end{tabular}

$\mathrm{C}=$ congenital cataract. $\mathrm{U}=$ unilateral. $\mathrm{B}=$ bilateral. $\mathrm{T}=$ unilateral traumatic cataract. $\mathrm{M}=$ microphthalmic eye. $\mathrm{CF}=$ counting fingers. $\mathrm{NK}=$ acuity not known. $\mathrm{NR}=$ not refracted. at the age of 4 years. A correction of 32 dioptres was needed, but only half of this was achieved. Nevertheless, with amblyopia therapy vision in this eye has improved to $6 / 60$, and the patient is now $61 / 2$ years old. Patient 13 received only about $60 \%$ of the desired correction, and epikeratophakia may be repeated. Postoperative binocular function has been recorded in two cases; patient 2 can fuse images on the synoptophore over a limited range, and patient 14 achieves rudimentary stereopsis. Patient 15 has had his epikeratophakia lens removed as detailed below.

\section{APHAKIA - COMPLICATIONS}

Both epikeratophakia lenses that were glued in place became dislodged by the second postoperative day. Both lenses were removed, and new lenses were sutured in place without further complication.

Two cases failed to epithelialise postoperatively despite intensive inpatient management including the use of bandage contact lenses, eye pads, and lid taping. In both cases it proved necessary to remove the epikeratophakia lens about four weeks after surgery. In one case there was no obvious reason, but the other patient (number 15 in the paediatric aphakia group) had severe icthyosis, which may have been contributory.

Two cases had epithelial breakdowns after uncomplicated initial epithelialisation. The first developed a linear defect two months after surgery. This was treated with topical antibiotics only, and healed within one week. The second patient had a larger area of defect that occurred at two weeks. This was managed with a bandage contact lens. This defect recurred at three months and was again successfully managed with a contact lens, leaving a clear epikeratophakia lens. One patient has had recurrent filamentary keratitis that has required topical acetyl cysteine $5 \%$; the lens has remained clear.

Late lens removal, between six and 13 months after surgery, has been required in eight cases. Under topical anaesthesia the wing of the lens was dissected out of its pocket, and then the lens peeled away easily from the host cornea. In all these patients re-epithelialisation was without problems. Five lenses were removed for incorrect refractive result (an average of 5.8 dioptres of undercorrection). One lens was removed for high astigmatism (7 dioptres), one when the penetrating keratoplasty that it was sewn over failed, and one removed when visual

TABLE II Results in keratoconus

\begin{tabular}{lllll}
\hline $\begin{array}{l}\text { Patient } \\
\text { no. }\end{array}$ & $\begin{array}{l}\text { Follow-up } \\
\text { (months) }\end{array}$ & $\begin{array}{l}\text { Preop. } \\
\text { acuity }\end{array}$ & $\begin{array}{l}\text { Postop. } \\
\text { acuity }\end{array}$ & Postop refraction \\
\hline 1 & 15 & CF & $6 / 9$ & $1 \cdot 00 /-2 \cdot 00 \times 142$ \\
2 & 11 & $6 / 18$ & $6 / 9$ & $2 \cdot 00 /-2 \cdot 00 \times 20$ \\
$3^{\star}$ & 9 & CF & $6 / 12$ & $-3 \cdot 50 /-11 \cdot 00 \times 50$ \\
4 & 9 & $6 / 60$ & $6 / 6$ & $-0 \cdot 50 /-2 \cdot 00 \times 90$ \\
5 & 5 & $6 / 24$ & $6 / 9$ & $-8 \cdot 00 /-2 \cdot 25 \times 70$ \\
6 & 3 & CF & $6 / 9$ & $-11 \cdot 00 /-2 \cdot 00 \times 50$ \\
7 & 3 & $6 / 60$ & $6 / 9$ & $0 \cdot 50 /-3.50 \times 107$ \\
8 & 1 & $6 / 36$ & & NR \\
9 & 1 & CF & & NR \\
\hline
\end{tabular}

$\mathrm{CF}=$ counting fingers. $\mathrm{NR}=$ not refracted. $\star$ Patient 3 had 2 dioptres of astigmatism three months after surgery, 5 dioptres at six months and finally, 11 dioptres at eight months. At this time the epikeratophakia lens was removed and penetrating keratoplasty performed. 
acuity failed to improve beyond $6 / 24$ despite a preoperative acuity of 6/9. Four patients have since received a secondary lens implant, two have had repeat epikeratophakia, and two have not had further surgery.

Interface opacities have not been an important problem. In five cases typical small, midperipheral, putty grey areas have appeared at the interface. All these patients have now been followed up for at least six months, and the areas of presumed epithelial cell proliferation do not appear to be progressing and none impinge on the visual axis.

KERATOCONUS

Table 2 shows the results for each keratoconus patient. All patients were intolerant of contact lenses, and the preoperative acuity shown is the best that was possible with spectacle correction. Six out of seven patients $(86 \%)$ with more than two months' follow-up achieved a good result with spectacle corrected acuity of $6 / 9$ or better. The remaining patient achieved $6 / 12$ but with very high cylinder and required penetrating keratoplasty.

MYOPIA

The single myopic patient treated has a preoperative refraction of -15 dioptres in the right eye (acuity 6/9) and -30 dioptres in the left (acuity 6/36). Epikeratophakia was performed on the left eye, aiming to balance its refraction to that of the right eye. After one month of follow-up the acuity in the left eye was $6 / 60$ with a correction of -15 dioptres.

\section{Discussion}

The improvement in the results over the series, in terms of spherical error and astigmatism, represents a learning curve for both lens manufacture and surgical technique.

Twelve $(21 \%)$ of the aphakic lenses were removed. This is a rather higher proportion than found in the other series where overall $6 \%$ of over 900 were removed. ${ }^{4-9}$ Seven of the 12 removals in this series may be attributed to the learning curve; five were removed for serious undercorrection, and two were removed following the use of fibrin glue. One lens failed because of underlying graft failure.

Results in paediatric aphakia are difficult to compare from study to study. Paediatric patients form a very diverse group with varying ages, often unknown duration of cataract, and varying times from cataract surgery to correction of aphakia. Maintaining full time contact lens correction is difficult, and the delay in restoring clarity after epikeratophakia may be important. Refraction and acuity are difficult to assess, and problems in maintaining occlusion limit the results of amblyopia therapy. Babies under the age of 1 year were not considered for epikeratophakia in this study, as it has been found that in this age group there is a marked shift to myopia as the eye grows. ${ }^{19}$ Children beyond the age when amblyopia is a problem who suffer traumatic cataract often choose not to persevere with contact lens correction, lose binocular function, and their vision becomes divergent. The presence or rudimentary stereopsis in paediatric patient 14 is therefore encouraging.

Postoperative epithelialisation appeared to be much faster in this series than in many others. Apart from the two cases where primary re-epithelialisation failed, every eye was fully epithelialised by seven days, with an average time of less than four days. In contrast other reports have variously found only $75 \%$ epithelialised by one week, ${ }^{20}$ average times to reepithelialisation of 13 days, ${ }^{21}$ and $15 \%$ of cases taking more than two weeks. ${ }^{12}$ The explanation for this and for the fact that in this series routine use of bandage contact lenses, eye pads, or lid sutures did not seem necessary, may relate to the manufacturing and surgical techniques used. Most lenses used in this series were not lyophilised. Lyophilisation is needed to ship lenses, but the process inflicts additional damage to Bowman's layer of the lens ${ }^{22}$ and so may inhibit re-epithelialisation. The surgical technique used prevented alcohol from damaging peripheral cornea which may otherwise have retarded reepithelialisation.

The time course for the recovery of visual acuity has not previously been reported with survival (Kaplan-Meir type) analysis. Reports agree, however, that many months may be required for recovery of visual acuity after surgery. ${ }^{41012}$ The $83 \%$ of patients in this study who achieved an acuity within 1 Snellen line of the preoperative value by nine months is very close to the $82 \%$ that achieved this level more than three months after suture removal in a study of 150 patients. ${ }^{4}$

The reduction found in contrast sensitivity, especially in the presence of glare, may explain the subjective experience of some patients that their epikeratophakic eye does not provide as good vision as their fellow eye. The reduction in contrast sensitivity has been confirmed elsewhere, ${ }^{23}$ and comparison has been made with contrast sensitivity of phakic and contact lens corrected eyes. ${ }^{18}$

The single case of myopia resulted in the desired refractive correction, and the patient is delighted with the result. The largest reported series of myopic epikeratophakia found that $58 \%$ of patients were corrected to within $20 \%$ of the required refraction. ${ }^{5}$ In comparison with the corresponding series of adult aphakia, it was necessary to remove over twice as many lenses in the myopic group. Serious overcorrection of the refractive error seems to be more of a problem with myopic than with aphakic corrections. ${ }^{24}$ Myopic lenses are no longer supplied by Allergan Medical Optics, who are now concentrating research on other means of correcting myopia. ${ }^{20}$

The results from this study are broadly similar to those reported elsewhere. The main difference is that patients treated in the early part of this study had relatively inaccurate refractive corrections. Improved lathing formulae later eliminated this difference.

Epikeratophakia for aphakia is a far from perfect operation. The majority of patients may expect to need spectacle overcorrection, and about one-quarter will be more than 3 dioptres 
from the desired refraction. Furthermore the quality of vision is suboptimal, with reduced contrast sensitivity especially in the presence of glare. For keratoconus the results so far seem highly encouraging. Patients have had restoration of good spectacle acuity without the need for penetrating keratoplasty. There are not enough myopic patients in this series to enable a firm conclusion to be reached, but the solitary case treated has done well.

Selection of patients for epikeratophakia is, as with any operation, dependent on balancing the probable benefits with the potential complications. This study has confirmed that epikeratophakia is a very safe and mostly reversible procedure.

For aphakia epikeratophakia is indicated where spectacle or contact lens correction is impracticable and where a secondary implant is either impossible, such as following severe anterior segment trauma, or highly inadvisable, such as in children. Where a secondary anterior chamber implant is technically feasible, a decision must be made in each individual case where the increased safety of epikeratophakia over intraocular surgery justifies the relatively poor accuracy of refractive result, reduced contrast sensitivity, and delay in visual recovery.

For keratoconus the results so far favour epikeratophakia as the preferred management of patients with poor spectacle acuity and contact lens intolerance who have good diagnostic contact lens acuity. The more invasive penetrating keratoplasty may be performed if epikeratophakia subsequently fails. Epikeratophakia is a potentially valuable addition to the armamentarium of the ophthalmic surgeon. For carefully selected patients it can provide worthwhile visual improvement without the risk of intraocular surgery.

My thanks to the British Medical Association for their generous support via the Middlemore Fund and to the surgeons of Moorfields Eye Hospital for their advice and support.

1 Binder PS, Zambia EY. Why do some epikeratoplasties fail? Arch Ophthalmol 1987; 105: 63-9.
2 Tamaki K, Yamaguchi T, McDonald MB, Kaufman HE. Histological study of epikeratophakia tissue lenses for myopia removed from two patients. Ophthalmology 1986; 93: 1502-8.

3 Goodman GL, Peiffer RL, Werblin TP. Failed epikeratoplasty for keratoconus. Cormea 1986; 5: 29-34.

4 McDonald MB, Kaufman HE, Aquavella JV, et al. The nationwide study of epikeratophakia for aphakia in adults. Am F Ophthalmol 1987; 103: 358-65.

5 McDonald MB, Kaufman HE, Aquavella JV, et al. The nationwide study of epikeratophakia for myopia. Am $\mathcal{J}$ Ophthalmol 1987; 103: 375-83.

6 McDonald MB, Kaufman HE, Durrie DS. Epikeratophakia for keratoconus, the nationwide study. Arch Ophthalmol 1986; 104: 1294-300.

7 Morgan KS, McDonald MB, Hiles DA, et al. The nationwide study of epikeratophakia for aphakia in children. $A m \mathcal{J}$ study of epikeratophakia for

8 Morgan KS, McDonald MB, Hiles DA, et al. The nationwide study of epikeratophakia for aphakia in older children. Ophthalmology 1988; 95: 526-31.

9 Uusitalo RJ, Lehtosalo J. Visual, refractive and keratometric results of epikeratophakia in children. A two year follow-up. Arch Ophthalmol 1989; 107: 358-63.

10 Durrie DS, Habrich DL, Dietze TR. Secondary intraocular implantation vs epikeratophakia for the treatment of aphakia. Am 7 Ophthalmol 1987; 103: 384-91.

11 Steinert RF, Wagoner MD. Long term comparison of epikeratoplasty and penetrating keratoplasty for epikeratoplasty and penetrating keratoplas

12 Lass JH, Stocker EG, Fritz ME, Collie DM. Epikeratoplasty: the surgical correction of aphakia, myopia and keratoconus. Ophthalmology 1987; 94: 912-25.

13 Dietze TR, Durrie DS. Indications and treatment of keratoconus using epikeratophakia. Ophthalmology 1988; 95: $236-44$

14 Halliday BL. Manufacture of epikeratophakia lens. Eye 1988; 2: 395-9.

15 Halliday BL. A computer program for the calculation of the back radius of cut for aphakia epikeratophakia lenses. In: Oliveira LNF de, ed. Ophthalmology today. Amsterdam: Elsevier, 1988: 145-51.

16 Halliday BL. Simplified formulas for lathing epikeratophakia lenses. Ophthalmic Surg 1989; 20: 337-41.

17 Steinert RF, Grene RB. Postoperative management of epikeratoplasty. 7 Cataract Refract Surg 1988; 14: 255-64

18 Harper RA, Halliday BL. Glare and contrast sensitivity in contact lens corrected aphakia, epikeratophakia and pseudophakia. Eye 1989; 3: 562-70.

19 Arffa RC, Marvelli TL, Morgan KS. Long-term follow-up of refractive and keratometric results of pediatric epikeratorefractive and keratometric results of pediation

20 AMO Kerato-Lens Update 1989; 6: no.1

21 Wagoner MD, Steinert RF. Temporary tarsorrhaphy enhances reepithelialization after epikeratoplasty. Arch Ophthalmol 1988; 106: 13-4.

22 Binder PS, Zavala EY, Baumgartner SD, Nayak SK. Combined morphologic effects of cryolathing and lyophilization on epikeratoplasty lenticules. Arch Ophthalmol 1986; 104: 671-9.

23 Mannis MJ, Zadnik K, Johnson C, Adams C. Contrast sensitivity function after epikeratophakia. Cornea 1988; 7: 280-4.

24 Nichols BD, Lindstrom RL, Spigelman AV. The surgical management of overcorrection in myopic epikeratophakia. Am F Ophthalmol 1988; 105: 354-6. 